Original article

\title{
EFFECTS OF PHOENIX DACTYLIFERA POLLEN GRAINS EXTRACT SUPPLEMENTATION ON POST-THAW QUALITY OF ARABIAN STALLION SEMEN
}

\author{
G. A. EL-SISY ${ }^{1}$, D. A. EL-BADRY ${ }^{2}$, R. I. EL-SHESHTAWY ${ }^{1} \&$ W. S. EL-NATTAT ${ }^{1}$ \\ ${ }^{1}$ Animal Reproduction and AI Department, Veterinary Researches Division, \\ National Research Centre, Dokki, Egypt; ${ }^{2}$ Department of Artificial Insemina- \\ tion and Embryo Transfer, Animal Reproduction Research Institute, \\ Agriculture Research Center, Giza, Egypt
}

\section{Summary}

El-Sisy, G. A., D. A. El-Badry, R. I. El-Sheshtawy \& W. S. El-Nattat, 2018. Effects of Phoenix dactylifera pollen grains extract supplementation on post-thaw quality of Arabian stallion semen. Bulg. J. Vet. Med., 21, No 1, 40-49.

\begin{abstract}
This study explored the effect of extender supplementation with different concentrations of date palm pollen grain (DPPG) on post-thawed sperm motility, viability index, membrane and acrosome integrities in Arabian stallions. Five ejaculates from each of four Arabian stallions were subjected to cryopreservation with a modified INRA-82, without any supplementation (control) or supplemented with 50, 100, 150, 200 and $250 \mathrm{mg}$ DPPG. After thawing, all samples were maintained at $37^{\circ} \mathrm{C}$, while analyses were performed at 0,1 , and 2 and 3 hours. Sperm motility percentage, viability index, membrane integrity percentage and acrosome integrity of each sample were determined by conventional laboratory methods. The addition of $100 \mathrm{mg}$ DPPG resulted in improved maintenance of sperm motility after 0 and $60 \mathrm{~min}$ post-thawing, as compared to the control and other treatment groups. Nonsignificant effects on viability index were observed after enrichment of extender with 100 and $150 \mathrm{mg}$ DPPG. The addition of 100 and $150 \mathrm{mg}$ DPPG resulted in significant $(\mathrm{P}<0.0010)$ improvement in post-thawing membrane integrity $(41.33 \pm 0.83 \% ; 41.33 \pm 2.33 \%)$ compared to the controls $(34.33 \pm 1.55 \%)$. These concentrations exerted also a beneficial effect in preserving sperm acrosome integrity $(38.33 \pm 1.01 \% ; 38.67 \pm 1.64 \%)$ as compared with the control one $(33.33 \pm 1.12 \%)$. Supplementation of modified INRA-82 with $200 \mathrm{mg}$ DPPG failed to maintain sperm motiliy while $250 \mathrm{mg}$ PG has a negative impact on all studied post-thawing semen parameters. In conclusion, adding 100 and $150 \mathrm{mg}$ date palm pollen grain extract to modified INRA- 82 seemed useful in the chilling and freezing process of Arabian stallion sperm.
\end{abstract}

Key words: Arabian stallion, cryopreservation, pollen grain, semen

\section{INTRODUCTION}

There is a continuous interest in the utilisation of herbal remedies in the develop- ing countries. At present, the use of herbal antioxidants to counteract the deleterious 
action of reactive oxygen species (ROS) and oxidative stress on body cells and tissues has attracted research attention. From ancient times, date palm pollen grain (DPPG, male germ powder of palm flowers) was used to improve reproductive performances in men and woman as dietary supplement. DPPG has a potent nutritive importance as it is rich in phytochemicals such as estrone, $\alpha$-amirin, triterpenoidal saponins, flavonoids estrone, estradiol, estriol and a crude gonadotrophic substance (Abedi et al., 2014).

Various studies have concluded that dietary supplementation could improve spermatogenesis, increase sperm counts, motility, and increase the concentration of testosterone, FSH and LH (Salman et al., 2014; Baharara et al., 2015; El-Kashlan et al., 2015; Rasekh et al., 2015). Also, DPPG is a rich source of natural antioxidants. El-Kashlan et al. (2015) observed that DPPG extract possessed a powerful free radical scavenging capacity. Hassan (2011) and Bishr \& Desoukey (2012) attributed the powerful antioxidant capacity of pollen grain to its high content of phenolic, carotenoid, flavonoid compounds, and considerable amount of vitamins A, E and $\mathrm{C}$. Moreover, pollens have antibacterial, antifungal and antiviral activity (Abedi et al., 2012; Mallhi et al., 2014).

Cryopreservation causes a wide range of chemical, physical and mechanical injures to sperm membranes of all mammalian species (Watson, 2000), which are attributed to temperature changes, alterations in the transition from the lipid phase, production of reactive oxygen species (ROS) and osmotic stress (Ortega Ferrusola et al., 2009; Câmara et al., 2011). Moreover, the overproduction of ROS causes oxidative stress that involves structural damage of sperm membranes, fall of intracellular ATP levels causing decrease in the viability and motility of cryopreserved sperm (Baumber et al., 2000; Agarwall \& Said, 2005). To alleviate the harmful effects of ROS, seminal plasma possesses powerful source of ROS scavengers which offer protection for equine sperm, including enzymes such as superoxide dismutase, catalase, glutathione peroxidase, and small molecular antioxidants such as ascorbic acid and $\alpha$ tocopherol (Aitken \& Baker, 2004; Sikka, 2004). Unfortunately, removal of seminal plasma during equine semen processing and consequent loss of these antioxidants may increase the vulnerability of sperm oxidative stress (Ball, 2008). Owing to the evidenced damaging effect of ROS to genomic material and sperm membranes, it is necessary to establish whether semen extender enriched with various antioxidants could improve the survival and fertility of cryopreserved equine sperm (Sinclair, 2000). The addition of natural extracts and infusions from plant sources to semen extenders was indicated in cattle and caprine sperm preservation for their protective, nutritive, antioxidant and antibacterial properties (Sansone, 2000). AlDujaily et al. (2012) concluded that the addition of $20 \% P$. dactylifera pollen extract to the culture medium of the in vitro sperm activation improved sperm motility. El-Sheshtawy et al. (2014) found out that the addition of aqueous extract of the DPPG to TRIS-citrate-fructose extender improved survival rates and semen quality after chilling and cryopreservation in bulls. To the best of our knowledge, only few studies have been conducted to evaluate the potency DPPG extract added to semen extender in preserving and maintaining sperm quality.

Despite the substantial flow of data on the promising quality and characteristics 
Effects of Phoenix dactylifera pollen grains extract supplementation on post-thaw quality of ....

of DPPG, few studies have so far been conducted to investigate the effect of enrichment of semen freezing extender with DPPG extracts on sperm viability after freeze thawing. The tendency for using natural antioxidants of plant origin is continuously increasing; therefore, the aim of this study was to investigate the efficacy of addition of aqueous extract of the DPPG to semen extender (modified INRA-82) on the stallion sperm's survival rates after freezing/thawing.

\section{MATERIALS AND METHODS}

\section{Preparation of extender}

Modified INRA-82 (mINRA-82) described by El-Badry et al. (2014) was used as base and control extender. This extender consists of $25 \mathrm{~g} / \mathrm{L}$ glucose monohydrate, $1.5 \mathrm{~g} / \mathrm{L}$ lactose monohydrate, $1.5 \mathrm{~g} / \mathrm{L}$ raffinose pentahydrate, 0.4 $\mathrm{g} / \mathrm{L}$ potassium citrate monohydrate, 0.3 $\mathrm{g} / \mathrm{L}$ sodium citrate dihydrate, $4.76 \mathrm{~g}$ HEPES, pH 7.0, $500 \mathrm{mg} / \mathrm{L}$ gentamycin, $0.035 \%$ SDS and $0.15 \%$ skimmed milk. All ingredients were dissolved in one liter of distilled water.

\section{Preparation of extract}

Pollen grain extract was prepared from the chafe of DPPG obtained from the palm tree pollen at El-Fayoum governorate. To 5 test tubes each containing $5 \mathrm{~mL}$ of mINRA-82 50, 100, 150, 200 and $250 \mathrm{mg}$ of this powder (El-Shehstawy et al., 2014) were added. All tubes were put in cooling incubator (adjusted at $5{ }^{\circ} \mathrm{C}$ ) for three days with daily vortexing and finally centrifuged to get the supernatant extenders (IPG-50, mIPG-100, mIPG-150, mIPG200 and $\mathrm{mIPG}-250$, respectively).

\section{Semen collection and processing}

On a once weekly collection schedule, five ejaculates per stallion were obtained from 4 Arabian stallions, aged 8-14 years, and individually housed at Police Academy stud, Cairo, Egypt. At the time of collection, early in the morning, a teaser estrus mare was used for the stallion to mount. Semen was collected using a lubricated and pre-warmed $\left(45\right.$ to $50^{\circ} \mathrm{C}$ ) Colorado model artificial vagina with an inline filter to separate the gel fraction.

Immediately following collection, the gel-free portion of the ejaculate was evaluated for volume and progressive motility. Sperm concentration was determined with a haemocytometer. Only ejaculates with at least $60 \%$ progressively motile sperm and $250 \times 10^{6}$ sperm cell $/ \mathrm{mL}$ were used for freezing. The semen was extended 1:1 (semen:extender) in mINRA82 warmed to $38{ }^{\circ} \mathrm{C}$. The diluted samples were placed into $15-\mathrm{mL}$ tubes and centrifuged for $10 \mathrm{~min}$ at $400 \times \mathrm{g}$. (Cochran et al., 1984). At least $95 \%$ of the supernatant was removed (Loomis, 2006) and each pellet was re-suspended with mINRA-82 (containing 5\% glycerol and 15\% egg yolk) enriched with DPPG (mIPG-50, mIPG-100, mIPG-150, mIPG-200, mIPG250) and mINRA-82 (control without DPPG) to a final sperm concentration of $100 \times 10^{6}$ motile sperm $/ \mathrm{mL}$. Each aliquot was cooled slowly to $5{ }^{\circ} \mathrm{C}$ over one hour under aerobic conditions, and then incubated at $5{ }^{\circ} \mathrm{C}$ for $30 \mathrm{~min}$ (Crockett et al., 2001). The extended semen was drawn into $0.5 \mathrm{~mL}$ straws (Minitube, Germany) and sealed thermally and placed $4 \mathrm{~cm}$ above liquid nitrogen in the vapour phase in foam box for $10 \mathrm{~min}$ before being plunged into the liquid phase (Cristanelli et al., 1985). The straws were then stored in goblets on canes and kept immersed in liquid nitrogen. For thawing, two straws 
per treatment were warmed in a water bath at $38^{\circ} \mathrm{C}$ for $30 \mathrm{~s}$.

\section{Evaluation of frozen-thawed semen}

Sperm motility was examined and recorded using a pre-warmed stage of phase contrast microscope $(200 \times)$ just after thawing, 1, 2 and $3 \mathrm{~h}$ post thawing. The post-thawing viability indices were calculated according to Milovanov (1962) to be equal to half of the post-thaw motility in addition to the summation of recorded motility at $1^{\text {st }}, 2^{\text {nd }}$ and $3^{\text {rd }}$ hours postthawing.

Hypo-osmotic swelling (HOS) positive cells percentage was determined using the procedure described by Nie \& Wenzel (2001). In brief, $100 \mu \mathrm{L}$ aliquot of each semen sample was mixed in $1.0 \mathrm{~mL}$ of a pre-warmed $100 \mathrm{mOsm}$ sucrose solution (1.712 $\mathrm{g}$ sucrose dissolved in $50 \mathrm{~mL}$ of sterile, deionized water). The mixture was incubated at $37{ }^{\circ} \mathrm{C}$ for $60 \mathrm{~min}$ in a $1.5 \mathrm{~mL}$ microcentrifuge tube. Following incubation, a small drop of sample was placed on a microscope slide and cover-slipped for examination by using phase contrast microscopy $(400 \times)$ to evaluate 100 spermatozoa for evidence of swelling and curling changes.
Sperm acrosomal integrity was estimated using fast green stain (Wells \& Awa, 1970).

\section{Statistical analysis}

One way analysis of variance and Duncan's multiple range tests (using SPSS program version 16.0) were done for the obtained data of frozen-thawed semen qualities after transformation of percentages to their corresponding arc-sin values (Snedecor \& Cochran, 1989). $\mathrm{P}<0.05$ was considered as statistically significant.

\section{RESULTS}

The results in Table 1 indicate a highly significant $(\mathrm{P}<0.0001)$ effect of adding $100 \mathrm{mg}$ DPPG to the mINA-82 extender on post-thawing stallion sperm motility. It resulted in improved maintenance of sperm motility after 0 and 60 min postthawing, compared to the control and other treatment groups, while the addition of $250 \mathrm{mg}$ DPPG failed to maintain sperm motility 60, 120, and 180 minute after thawing.

As shown in Table 2, non-significant effects were noticed for the addition of 100 and $150 \mathrm{mg}$ DPPG to mINRA-82

Table 1. Effect of date palm pollen grain (DPPG) addition to modified INRA-82 on post-thaw stallion sperm motility. Data are presented as mean \pm SEM, $n=15$

\begin{tabular}{llccc}
\hline \multirow{2}{*}{ Pollen enrichment } & \multicolumn{4}{c}{$\%$ motility after thawing (arc-sin values) } \\
\cline { 2 - 5 } & \multicolumn{1}{c}{0 hour } & 1 hour & 2 hours & 3 hours \\
\hline mINRA-82 (control) & $41.67^{\mathrm{bc}} \pm 0.63$ & $36.67^{\mathrm{b}} \pm 1.67$ & $31.67^{\mathrm{ab}} \pm 1.67$ & $25.00^{\mathrm{a}} \pm 1.09$ \\
mINRA-82+50 mg DPPG & $38.33^{\mathrm{cd}} \pm 0.63$ & $31.67^{\mathrm{c}} \pm 0.63$ & $26.67^{\mathrm{c}} \pm 0.63$ & $21.67^{\mathrm{b}} \pm 0.63$ \\
mINRA-82+100 mg DPPG & $48.33^{\mathrm{a}} \pm 1.67$ & $41.67^{\mathrm{a}} \pm 2.27$ & $33.33^{\mathrm{a}} \pm 1.67$ & $26.67^{\mathrm{a}} \pm 1.26$ \\
mINRA-82+150 mg DPPG & $43.33^{\mathrm{b}} \pm 2.27$ & $36.67^{\mathrm{b}} \pm 1.67$ & $31.67^{\mathrm{ab}} \pm 0.63$ & $25.00^{\mathrm{a}} \pm 1.09$ \\
mINRA-82+200 mg DPPG & $38.33^{\mathrm{cd}} \pm 1.67$ & $33.33^{\mathrm{bc}} \pm 1.67$ & $28.33^{\mathrm{bc}} \pm 1.67$ & $21.67^{\mathrm{b}} \pm 1.26$ \\
mINRA-82+250 mg DPPG & $35.00^{\mathrm{d}} \pm 1.09$ & $25.00^{\mathrm{d}} \pm 1.09$ & $18.33^{\mathrm{d}} \pm 0.63$ & $11.67^{\mathrm{c}} \pm 0.63$ \\
\hline
\end{tabular}

Different superscript letters within columns $(\mathrm{a}, \mathrm{b}, \mathrm{c})$ are significantly different $(\mathrm{P}<0.05)$ according to the Duncan multiple range test. 
Effects of Phoenix dactylifera pollen grains extract supplementation on post-thaw quality of ....

Table 2. Effect of date palm pollen grain (DPPG) addition to modified INRA-82 on post-thaw stallion sperm parameters. Data are presented as mean \pm SEM, $n=15$

\begin{tabular}{lrcc}
\hline \multirow{2}{*}{ Pollen enrichment } & \multicolumn{3}{c}{ Sperm parameters (arc-sin values) } \\
\cline { 2 - 4 } & \multicolumn{1}{c}{ Viability index } & HOS (\%) & Acrosome integrity (\%) \\
\hline mINRA-82 (control) & $114.00^{\mathrm{a}} \pm 1.09^{*}$ & $34.33^{\mathrm{b}} \pm 1.55$ & $33.33^{\mathrm{b}} \pm 1.12$ \\
mINRA-82+50 mg DPPG & $99.17^{\mathrm{b}} \pm 0.63$ & $32.33^{\mathrm{bc}} \pm 0.45$ & $31.00^{\mathrm{bc}} \pm 0.22$ \\
mINRA-82+100 mg DPPG & $125.83^{\mathrm{a}} \pm 1.26$ & $41.33^{\mathrm{a}} \pm 0.83$ & $38.33^{\mathrm{a}} \pm 1.01$ \\
mINRA-82+150 mg DPPG & $115.00^{\mathrm{a}} \pm 1.09$ & $41.33^{\mathrm{a}} \pm 2.33$ & $38.67^{\mathrm{a}} \pm 1.64$ \\
mINRA-82+200 mg DPPG & $102.50^{\mathrm{b}} \pm 1.26$ & $34.00^{\mathrm{b}} \pm 1.57$ & $32.00^{\mathrm{bc}} \pm 1.43$ \\
mINRA-82+250 mg DPPG & $72.50^{\mathrm{c}} \pm 0.63$ & $29.67^{\mathrm{c}} \pm 0.98$ & $29.00^{\mathrm{c}} \pm 1.15$ \\
\hline
\end{tabular}

Different superscript letters within columns $(\mathrm{a}, \mathrm{b}, \mathrm{c})$ are significantly different $(\mathrm{P}<0.05)$ according to the Duncan multiple range test.

extender in terms of post-thawing sperm viability index while highly significant effects $(\mathrm{P}<0.0001)$ were recorded for membrane and acrosome integrities when compared to the control (mINRA-82). Post-thawing viability index was insignificantly higher in mIPG-100 and mIPG-150 treatments $(125.83 \pm 1.26 ; 115.00 \pm 1.09)$ as compared with the control (114.00 \pm 1.09$)$. The addition of 100 and $150 \mathrm{mg}$ DPPG resulted in significant $(\mathrm{P}<0.0001)$ improvement in post-thawing membrane integrity $(41.33 \pm 0.83 \% ; \quad 41.33 \pm 2.33 \%)$ compared to the controls $(34.33 \pm 1.55 \%)$. Additionally, enrichment with 100 and $150 \mathrm{mg}$ DPPG was beneficial for the sperm acrosome integrity (38.33 $\pm 1.01 \%$; $38.67 \pm 1.64 \%)$ as compared with the control one $(33.33 \pm 1.12 \%)$. The supplementation of mINRA-82 with $200 \mathrm{mg}$ DPPG had no effect on all post-thawing semen parameters studied and it was nearly similar to control, meanwhile $250 \mathrm{mg}$ DPPG had negative impact on all studied postthawing semen parameters.

\section{DISCUSSION}

In recent years, extensive research has been conducted to investigate the effect of natural (of herbal, natural and plant origins) antioxidants such as ginseng (Park et al., 2016), curcumin (Shah et al., 2016), date palm pollen grains (El-Sheshtawy et al., 2014), honey bee (El-Sheshtawy et al., 2016a) and pomegranate juice (El-Sheshtawy et al., 2016b) on the viability of animal sperm during cooling and cryopresevation. DPPG is a fine powder material produced by male flowering date palm plants, necessary for plants pollination. DPPG has been considered as an herbal remedy ever since ancient times without any scientific rationale.

Because of the continuous research interest in bioactive plant-derived medicinal ingredients, we attempted to deduce whether addition of Phoenix dactylifera pollen, as natural antioxidants, can improve sperm's survivability when added to frozen-thawed Arabian stallion extended semen.

The results of our study indicated that the addition of $100 \mathrm{mg}$ DPPG to the stallion freezing extender proved to be beneficial for the sperm cells in terms of motility. Our results were in agreement with Al-Dujaily et al. (2012) who proposed that supplementing human sperm culture media with $20 \% P$. dactylifera pollen ex- 
tract resulted in improvement in the sperm motility. In a previous study, El-Sheshtawy et al. (2014) noticed significant improvement in bull sperm motility when $250 \mathrm{mg}$ aqueous extract of the DPPG included to the Tris-citrate-fructose extender for chilling and cryopreservation. The current results disagreed with our previous study in bulls which may be related to species-specific differences. The capability of sperm from different species to withstand the freezing process is variable, bovine sperm spermatozoa are more tolerant to freezing-thawing than the equine spermatozoa (Rodgers et al., 2014).

Motility is the most essential indicator of the in vivo sperm fertilising ability (Vijayaraghavan, 2003). The beneficial effect of pollen grain, on motility and viability has been proved in rabbits, rats, mice, and humans (Marbeen et al., 2005; Al-Sanafi et al., 2006; Bahmanpour, 2006; Faleh \& Sawad, 2006; Rasekh et al., 2015).

Our results showed that enriching stallion freezing extender with 100 and 150 mg pollen grain has advantageous effect on viability index, membrane and acrosome integrity compared to the control group. During cryopreservation, mammalian sperm is subjected to tremendous chemical and physical damage as a result of phase transition changes, osmotic stress and overproduction of reactive oxygen species (ROS) which results in increase lipid peroxidation of the membrane (Ortega Ferrusola et al., 2009; Câmara et al., 2011). In various animal species, including horses, lipid peroxidation has been documented as an important marker of oxidative stress and cryonic injury in spermatozoa (Aitken et al., 2007; Ortega Ferrusola et al., 2009). The main ROS scavengers in equine semen are glutathione peroxidase, superoxide dismu- tase, and catalase. Removal of seminal plasma during semen processing before freezing discard antioxidants present in semen and subjecting spermatozoa to extreme ROS injury (Aitken et al., 2007). Oxidative stress has deleterious effects on sperm membrane fluidity, integrity, and flexibility, characteristics linked with fertilising capacity (Said et al., 2005). AlFarasi et al. (2005) and Mansouri et al. (2005) reported the potent antioxidant activity of the aqueous extract of dates which was attributed its inclusion to the wide range of phenolic compounds including $p$-coumaric, ferulic and sinapic acids, flavonoids and procyanidins. Palm pollen has also been recognised as a rich source of phytochemicals and nutrients mainly carotenoids and flavonoids (Daoud et al., 2015). Fresh pollen has a highly nutritive value as it is rich in mineral, multi-vitamins, sugars, lipids, growth factors and more than 100 enzymes and cofactors (Hassan, 2011). Moreover, it is a superior source of protein, amino acid, fatty acid, enzymes, hormones (estrone, estradiol and estriol) and mineral salts (Alferz \& Campos, 2000).

Palm pollen contains an efficient material for improving semen quality and male fertility because it is rich in vitamins $\mathrm{A}, \mathrm{E}$ and $\mathrm{C}$ and it is a good source of minerals such as zinc, selenium, iron, cooper and cobalt (Hassan, 2011) that stimulates sperm motility and the progressive forward movement. All of these above mentioned components could improve sperm motility. Vitamin $\mathrm{C}$ is a naturally occurring antioxidant in seminal plasma (Anane \& Creppy, 2001) and is an essential cofactor of enzymes that are free radicals scavengers (Michael et al., 2008). It could possibly improve sperm function by reducing cell damage (Gangwar et al., 2015). On the other hand, $\alpha$-tocopherol, 
Effects of Phoenix dactylifera pollen grains extract supplementation on post-thaw quality of ....

one of the major sperm antioxidants, was established to be abundant in spermatozoa membrane (Suleiman et al., 1996; Surai et al., 2000) and protect sperm motility from oxidative harm (Brzezińska-Ślebodzińska et al., 1995). Besides, date palm pollen suspension was reported to have potent antimicrobial, antifungal and anti-toxicant activities (Aba Al-Khail et al., 2003; Shakibaa et al., 2011; Daoud et al., 2015) and these effects could improve postthawing semen quality through reduction of bacterial growth in the semen extender.

In conclusion, the inclusion of 100 and $150 \mathrm{mg}$ date palm pollen grain extract in modified INRA-82 had a beneficial effect on the chilling and freezing process of Arabian stallion sperm.

\section{ACKNOWLEDGEMENTS}

The authors are greatly indebted to the $\mathrm{Na}$ tional Research Center and the Police Academy stud for their helpful and valuable aids and all the facilities they presented to achieve the present article.

\section{REFERENCES}

Aba Al-Khail, A. A., J. H. Ibrahim \& K. M. Waveform, 2003. A Practical Book in Microbiology, Riyadh, Saudi Arabia.

Abedi, A., M. Parviz, S. M. Karimian \& H. R. Sadeghipour Rodsari, 2012. The effect of aqueous extract of Phoenix dactylifera pollen grain on sexual behavior of male rats. Journal of Physiology and Pharmacology Advances, 2, 235-342.

Abedi, A., S. M. Karimian, M. Parviz, P. Mohammadi, H. Reza \& S. Roudsari, 2014. Effect of aqueous extract of Phoenix dactylifera pollen on dopamine system of nucleus accumbens in male rats. Neuroscience \& Medicine, 5, 49-59.

Agarwall, A. \& T. M. Said, 2005. Oxidative stress, DNA damage and apoptosis in male infertility: a clinical approach. BJU International, 95, 503-507.

Aitken, R. J. \& M. A. Baker, 2004. Oxidative stress and male reproductive biology. Reproduction, Fertility Development, 16, 581-588.

Aitken, R. J., J. K. Wingate, G. N. De Iuliis \& E. A. McLaughlin, 2007. Analysis of lipid peroxidation in human spermatozoa using BODIPY C11. Molecular Human Reproduction, 13, 203-211.

Al-Dujaily, S. S., N. J. Al-Shahery \& A. A. Zabbon, 2012. Effect of Phoenix dactylifera pollen on in vitro sperm activation of infertile men. Al-Mustansiriyah Journal of Science, 23, 27-34.

Al-Farasi, M., C. Alasalvar, A. Morris, M. Baron \& F. Shahidi, 2005. Compositional and sensory characteristics of three native sun dried date (Phoenix dactylifera L.) varieties grown in Oman. Journal of Agriculture and Food Chemistry, 53, 7586-7591.

Alferz, M. J. M. \& M. S. Campos, 2000. Beneficial effect of pollen and or propels on the iron, calcium, phosphorus and magnesium in rats with nutritional ferropenic anemia. Journal of Agriculture and Food Chemistry, 48, 5715-5722.

Al-Sanafi, A. I., E. F. Bahaaldeen, M. I. Marbeen \& M. M. Marbut, 2006. The effect of date palm pollen and zinc sulphate in the treatment of human male infertility. Tikrit Journal of Pharmaceutical Science, 2, 31-34.

Anane, R. \& E. E. Creppy, 2001. Lipid peroxidation as pathway of aluminum cytotoxicity in human skin fibroblast cultures: Prevention by superoxide dismutase and catalase and vitamins E and C. Human \& Experimental Toxicology, 20, 477-481.

Baharara, J., E. Amini, F. S. Abdollahi, N. Nikdel \& M. A. Samani, 2015. Protective effect of date palm pollen (Phoenix dactylifera) on sperm parameters and sexual hormones in male NMRI mice exposed to low frequency electromagnetic field (50 Hz). Journal of Herbmed Pharmacology, 4, 75-80. 
Bahmanpour, S., T. Talaei, Z. Vojdani, M. R. Panjehshahin, A. Poostapasand, S. Zareei \& M. Ghaeminia, 2006. Effect of Phoenix dactylifera pollen on sperm parameters and reproductive system of adult male rats. Iranian Journal of Medical Sciences, 31, 208-212.

Ball, B. A., 2008. Oxidative stress, osmotic stress and apoptosis: Impacts on sperm function and preservation in the horse. Animal Reproduction Science, 107, 257-267.

Baumber, J., B. A. Ball, C. G. Gravence, V. Medina \& M. C. Davies-Morel, 2000. The effect of reactive oxygen species on equine sperm motility, viability, acrosomal integrity, mitochondrial membrane potential, and membrane lipid peroxidation. Journal of Andrology, 21, 895-902.

Bishr, M. \& S. Y. Desoukey, 2012. Comparative study of the nutritional value of four types of egyptian palm pollens. Journal of Pharmacy and Nutrition Sciences, 2, 50-56.

Brezezińska-Slebodzińska, E., A. B. Slebodziński, B. Pietras \& G. Wieczorek, 1995. Antioxidant effect of vitamin $\mathrm{E}$ and glutathione on lipid peroxidation in boar semen plasma. Biological Trace Element Research, 47, 69-74.

Bucak, M. N., A. Atessahin \& A. Yuce, 2008. Effect of anti-oxidants and oxidative stressparameters on ram semen after the freeze-thawing process. Small Ruminant Research, 75, 128-134.

Câmara, D. R., S. V. Silva, F. C. Almeida, J. F. Nunes \& M. M. Guerra, 2011. Effects of antioxidants and duration of prefreezing equilibration on frozen-thawed ram semen. Theriogenology, 76, 342-350.

Cochran, J. D., R. P. Amann, D. P. Froman, B. W. Pickett, 1984. Effects of centrifugation, glycerol level, cooling to $5{ }^{\circ} \mathrm{C}$, freezing rate and thawing rate on the post-thaw motility of equine sperm. Theriogenology, 22, 25-38.

Cristanelli, M. J., R. P. Amann, E. L. Squires \& B. W. Pickett, 1985. Effects of egg yolk and glycerol level in lactose-EDTA-egg yolk extender and of freezing rate on the motility of frozen-thawed stallion spermatozoa. Theriogenology, 23, 25-38.

Crockett, E. C., J. K. Graham, J. E. Bruemmer, E. L. Squires, 2001. Effect of cooling of equine spermatozoa before freezing on post-thaw motility: Preliminary results. Theriogenology, 55, 793-803.

Daoud, A., D. Malika, S. Bakari, N. Hfaiedh, K. Mnafgui, A. Kadri \& N. Gharsallah, 2015. Assessment of polyphenol composition, antioxidant and antimicrobial properties of various extracts of Date Palm Pollen (DPP) from two Tunisian cultivars. Arabian Journal of Chemistry, (in press).

El-Badry, D. A., A. M. Anwer, Z. M. Rawash, 2014. Effect of different concentrations of sodium dodecyl sulfate, egg yolk and glycerol on the freezability and DNA integrity of Arabian stallion spermatozoa. Assiut Veterinary Medical Journal, 60, 29-35.

El-Kashlan, A. M., M. M. Nooh, W. A. Hassan \& S. M. Rizk, 2015. Therapeutic potential of date palm pollen for testicular dysfunction induced by thyroid disorders in male rats. PLoS ONE, DOI:10.1371/ journal.pone. 0139493 .

El-Sheshtawy, R. I., W. S. El-Nattat, A. H. Ali \& H. A. Sabra, 2014. The effect of Phoenix dactylifera pollen grains tris-infusion on semen preservability of local bull breeds. Global Veterinaria, 13, 728-732.

El-Sheshtawy, R. I., D. A. El-Badry, G. A. ElSisy, W. S. El-Nattat \& A. M. Abo Almaaty, 2016a. Natural honey as a cryoprotectant to improve Arab stallion post-thawing sperm parameters. Asian Pacific Journal of Reproduction, 5, 331-334.

El-Sheshtawy, R. I., G. A. El-Sisy, \& W. S. El-Nattat, 2016b. Effects of pomegranate juice in Tris-based extender on cattle semen quality after chilling and cryopreservation. Asian Pacific Journal of Reproduction, 5, 335-339.

Faleh, B. H. \& A. A. Sawad, 2006. Effect of palm pollen grains extracts (Phoenix dactylifera L) on spermatogenic activity of male rabbits. Basrah Journal For Date Palm Research, 5, 1-10. 
Effects of Phoenix dactylifera pollen grains extract supplementation on post-thaw quality of ....

Gangwar, C., S. D. Kharche, R. Ranjan, S. Kumar, A. K. Goel, S. K. Jindal \& S. K. Agarwal, 2015. Effect of vitamin C supplementation on freezability of Barbari buck semen. Small Ruminant Research, 129, 104-107.

Hassan, H. M. M., 2011. Chemical composition and nutritional value of palm pollen grains. Global Journal of Biotechnology and Biochemistry, 6, 1-7.

Loomis, P. R., 2006. Advanced methods for handling and preparation of stallion semen. Veterinary Clinics of North America: Equine Practice, 22, 663-676.

Mallhi, T. H., M. I. Qadir, M. Ali, B. Ahmad, Y. H. Khan \& R. A. Ajwa, 2014. Date (Phoenix dactylifera): An emerging plant in pharmacological research. Pakistan Journal of Pharmaceutical Sciences, 27, 607-616.

Mansouri, A., G. Embarek, E. Kokkalou \& P. Kefalas, 2005. Phenolic profile and antioxidant activity of the Algerian ripe date palm fruit (Phoenix dactylifera). Food Chemistry, 89, 411-420.

Marbeen, M. I., A. E. Al-Snafi, M. M. Marbut \& I. Y. Allahwerdy, 2005. The probable therapeutic effects of date palm pollen in the treatment of male infertility. Tikrit Journal of Pharmaceutical Sciences, 1 , 30-35.

Michael, A., C. Alexopoulos \& E. Pontiki, 2008. Quality and reactive oxygen speciesof extended canine semen after vitamin C supplementation. Theriogenology, 70, 827-835.

Milovanov, V. K., 1962. Reproductive Biology and Artificial Insemination of Animals. Selhozgiz, Moscow (RU).

Nie, G. J. \& J. G. W. Wenzel, 2001. Adaptation of the hypo-osmotic swelling test to assess functional integrity of stallion spermatozoal plasma membranes. Theriogenology, 55, 1005-1018.

Ortega Ferrusola, C., L. González Fernández, J. M. Morrell, C. Salazar Sandoval, B. Macías García, H. Rodríguez-Martinez, J. A. Tapia, F. J. Peña, 2009. Lipid peroxida- tion, assessed with BODIPY-C11, increases after cryopreservation of stallion spermatozoa, is stallion dependent and is related to apoptotic-like changes. Reproduction, 138, 55-63.

Park, H. J., S. Choe \& N. C. Park, 2016. Effects of Korean red ginseng on semen parameters in male infertility patients: A randomized, placebo-controlled, double-blind clinical study. Chinical Journal of Integrative Medicine, 22, 490-495.

Rasekh, A., H. K. Jashni, K. Rahmanian \& A. S. Jahromi, 2015. Effect of palm pollen on sperm parameters of infertile man. Pakistan Journal of Biological Sciences, 8, 196-199.

Rodgers, R. S., H. King \& R. Hopper, 2014. Effect of low density lipoprotein (LDL) on stallion sperm motility after cryopreservation. Journal of Equine Veterinary Science, $\mathbf{3 4}, 80$.

Said, T., A. Agarwal, S. Grunweld, M. Rasch, T. Baumann, C. Kriegel, L. Li, H Glander, A. J. Thomas Jr. \& U. Paasch, 2005. Selection of non-apoptotic spermatozoa as a new tool for enhancing assisted reproduction outcomes: An in vivo model. Biology of Reproduction, 74, 80-87.

Salman, I., A. Munazza, M. A. Hina, S. Tahir, A. Yasir \& E. N. Gul, 2014. Evaluation of spermatogenesis in prepubertal albino rats with date palm pollen supplement. African Journal of Pharmacy and Pharmacology, 8, 59-65.

Sansone, G., M. J. F. Nastri \& A. Fabbrocini, 2000. Storage of buffalo (Bubalus bubalis) semen. Animal Reproduction Science, 62, 55-76.

Shah, S. A., S. M. Andrabi \& I. Z. Qureshi, 2016. Freezability of water buffalo bull (Bubalus bubalis) spermatozoa is improved with the addition of curcumin (diferuoyl methane) in semen extender. Andrologia, doi: 10.1111/and.12713.

Shakiba, M., A. Kariminik \& P. Parsia, 2011. Antimicrobial activity of different parts of Phoenix dactylifera. International Journal 
of Molecular and Clinical Microbiology, 1, 107-111.

Sikka, S. C., 2004. Role of oxidative stress and antioxidants in andrology and assisted reproductive technology. Journal of Andrology, 25, 5-18.

Sinclair, S., 2000. Male Infertility: Nutritional and environmental considerations. Alternative Medicine Review, 5, 28-38.

Snedecor, G. W. \& Cochran, W. G., 1989. Statistical Methods, $8^{\text {th }}$ edn, Iowa State University Press, Ames, IA, USA.

Suleiman, S. A., M. E. Ali, Z. M. Zaki, E. M. El-Malik \& M. A. Nasr, 1996. Lipid peroxidation and human sperm motility: protective role of vitamin E. Journal of Andrology, 17, 530-537.

Surai, P. F., J. P. Brillard, B. K. Speake, E. Blesbois, F. Seigneurin \& N. H. Sparks, 2000. Phospholipid fatty acid composition, vitamin E content and susceptibility to lipid peroxidation of duck spermatozoa. Theriogenology, 53, 1025-1039.

Vijayaraghavan, S., 2003. Sperm motility: patterns and regulation. In: Introduction to Mammalian Reproduction, ed D. Tulsiani, Kluwer Academic Publishers, Boston, USA. pp. 79-91.
Watson, P. F., 2000.The causes of reduced fertility with cryopreserved semen. Animal Reproduction Science, 60-61, 481-492.

Wells, M. E. \& O. A. Awa, 1970. New technique for assessing acrosomal characteristics of spermatozoa. Journal of Dairy Science, 53, 327-332.

Paper received 27.05.2016; accepted for publication 30.09.2016

\section{Correspondence:}

Walid S. El-Nattat

Animal Reproduction and AI Department, Veterinary Researches Division,

National Research Centre, Dokki, Egypt, e-mail: elnattat@gmail.com 